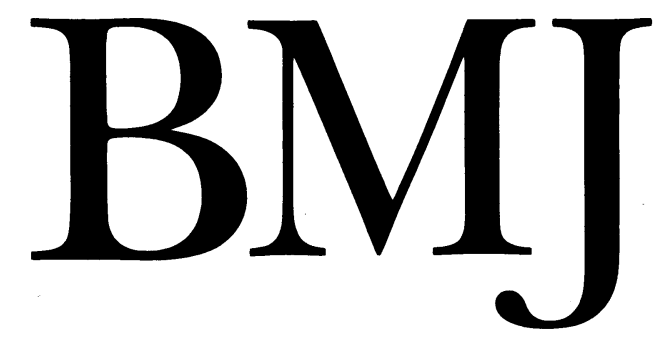

\title{
Choice and chance in low risk maternity care
}

\section{General practitioner obstetrics back on the agenda}

"Will I still have a choice about where I have my baby? Yes."

Despite claims that "under the new arrangements . . . popular cottage hospitals will thrive"' closures of small maternity units continue in line with the view that every woman should give birth in a district general hospital. As a result, in many parts of the country choice has been narrowing rather than widening. Between 1980 and 1990 the number of isolated general practitioner maternity units in the United Kingdom halved (from 212 to 106) while the number of units offering both general practitioner and consultant care fell slightly (from 121 to 115$){ }^{3}$ This might be interpreted as meaning that women preferred consultant care, but many of the closures were met with vociferous and concerted opposition from the users of the units.

Only 6\% of deliveries in England and Wales were booked for general practitioner care in $1988,{ }^{4}$ compared with $15 \%$ in 1975 and $50 \%$ in $1946 .{ }^{5}$ In $1988,31 \%$ of hospital deliveries for which general practitioners had overall responsibility took place in separate units alongside consultant units, with $42 \%$ in fully integrated units and $27 \%$ in isolated units. ${ }^{4}$ Lack of local facilities, absence of incentives, inappropriate training, and low confidence may mean that this form of care becomes extinct despite the efforts of the professionals concerned, who have formed an association, recently renamed the Association for Community-based Maternity Care, to defend it. ${ }^{6}$

Last year the $B M \mathcal{F}$ published two papers presenting data from integrated ${ }^{7}$ and isolated ${ }^{8}$ units, suggesting that general practitioner obstetrics is less safe than care offered by consultant obstetricians. These conclusions run counter to a substantial body of evidence from elsewhere.$^{69-18} \mathrm{~A}$ paper from Bradford failed to distinguish between deaths that could and could not have been prevented by better care and failed to take account of possible differences in the socioeconomic background of women booked for consultant and general practitioner care. ${ }^{719}$ Together with subsequent correspondence ${ }^{20-22}$ it identified problems of communication between professionals in Bradford. The paper's conclusions should therefore not be extrapolated elsewhere. It is encouraging to see that the general practitioners describing the outcome of planned births in this issue acknowledge cooperation and support from senior hospital doctors ( $p$ 1517)..$^{23}$

The authors of the other controversial study restricted their comparison of mortality in different types of unit to normal deliveries by excluding multiple births and all babies with lethal congenital malformations or birth weights under 2500 g. ${ }^{8}$ Antepartum stillbirths were included, although deciding whether the place of birth was relevant to this outcome is impossible without more details of each case. ${ }^{24}$ The authors also failed to take account of risk factors other than parity. ${ }^{2526}$ They reported higher perinatal mortality rates in the isolated units than in the integrated unit or the consultant unit for nulliparous and multigravid women and for both groups combined, and the $\chi^{2}$ tests showed that the differences were significant. In each of the three tests, however, one of the cells had an expected value of less than five. This means they should be interpreted with extreme caution and do not provide an adequate basis on which to recommend major changes in practice. ${ }^{26}$

Figures from the Office of Population Censuses and Surveys show that from 1975 to 1987 mortality for births in hospitals without obstetric units were low and fell in line with the rates for all births. ${ }^{27} 28$ Although these data do not identify women who booked for general practitioner units but transferred to consultant units, studies that have done so have shown that mortality in general practitioner units is low..$^{10-12}$

These studies do not attempt to control for selection biases, but several others have tried to do this by comparing groups of low risk women delivering with different forms of care. ${ }^{1314}$ Unlike the recent study from the Bath district, ${ }^{8}$ these failed to show that increased mortality was associated with general practitioner deliveries. Furthermore, a review of many such studies, mainly from the United Kingdom and North America, found only one where general practitioner care was associated with poorer outcome. ${ }^{15}$ Marjorie Tew has even claimed that general practitioner care is associated with lower mortality for high as well as low risk women, ${ }^{29}{ }^{30}$ but the nature of the selection processes and the predictive ability of the prediction scores she used has been questioned. ${ }^{931}$

Few studies of morbidity in mothers and babies have been done. Two studies comparing similar groups of low risk women delivering in hospital under general practitioner and consultant care found that higher morbidity was associated with consultant care. ${ }^{32}{ }^{33}$ Those comparing home and hospital births, including two restricted to low risk women, produced similar findings. ${ }^{34} 35$

The view that large hospitals are safer has been widely accepted ${ }^{36}$ without critical examination of the evidence. ${ }^{9}$ Some research from other countries suggests that larger babies actually do worse in larger hospitals, ${ }^{37-39}$ although an Australian study found the opposite. ${ }^{40}$ 
A recent study confirmed the well established finding that a considerable demand exists for care other than that found in consultant obstetric units. ${ }^{+1}$ Nearly all studies of women who have experienced both home and hospital births have indicated strong preferences for home delivery, although once again, there are problems with selection biases. ${ }^{9}$ No evidence exists that they are just "fuddy duddy middle class mothers" as has been suggested. ${ }^{+2}$ The experience of the general practitioners writing in this issue is that a substantial number of working class women will opt for home birth if the service is available and they are now receiving requests for it from Moslem women. ${ }^{2}$

A common reason advanced for closing isolated general practitioner maternity units is cost, often in response to short term financial problems, with some closures being classed as "cost improvement programmes." Ironically, this contrasts with what is happening in the United States, where "out of hospital birth centres" are just beginning to find favour on the grounds of cheapness. A review of the few studies done in the United Kingdom has found no evidence that general practitioner maternity care is uneconomic for the public sector or for its users..$^{43} \mathrm{~A}$ statutory requirement exists to provide a domiciliary midwifery service, and if this is integrated with hospital and community services no additional staff are needed. Closing small units, on the grounds of "rationalisation," will probably result in costs being transferred from the NHS to families, social services, or social security. The NHS may actually lose resources raised by volunteers as they may not transfer their support to the district general hospital when a small unit closes. ${ }^{43}$

\section{Parents want choice}

Parents are looking for choice, and ways must be found to provide it safely and economically to fulfil the government's promise that health authorities "will aim to provide you and your general practitioner with the maximum choice." positive step would be formally to recognise and enhance the role of midwives as specialists in normal delivery and experiment with new arrangements, such as midwifery care wards. ${ }^{44}$ The role of general practitioners in normal delivery should be reviewed. ${ }^{45}$ In many cases already the term "general practitioner delivery" is a misnomer as most such deliveries are normal, taking place under the supervision of midwives with variable input from general practitioners.

Training is also important. Although most entrants to general practice have some training in obstetrics, it is mainly in consultant units. A chance to experience maternity care in a low technology setting should be part of the training of all general practitioners and midwives. The further problem of maintaining skills could be approached by interchange of midwifery staff between different types of unit and expanding the numbers of clinical assistant and hospital practitioner appointments. The latter would provide general practitioners who are regularly involved in intrapartum care with an opportunity to maintain and develop their skills, while also assisting staffing of obstetric departments by providing relatively long term appointments at subconsultant level. Finally, transfer of women during pregnancy should not be all one way. Women referred to obstetricians for investigation of problems should be transferred back to the care of their general practitioner or midwife if consultant care is not required.

To fulfil the government's promise of choice attention must be refocused on the needs of the majority of women who are unlikely to need an obstetrician at delivery and whose babies are at low risk of developing problems. Wherever women choose to deliver, midwives will provide most of their care, although some general practitioners may still want to be involved. Suitably organised and rewarded, this can be only to the benefit of all concerned, including the hard pressed consultant service.

Department of Social Administration and Policy,

University of Ulster at Jordanstown,

Newtownabbey,

County Antrim BT37 0QB

National Perinatal Epidemiology Unit,

Radcliffe Infirmary,

Oxford OX2 6HE

Brecon Medical Group Practice, RONA CAMPBELL

Ruperra House,

Brecon,

Powys LD3 7AA

ALISON MACFARLANE

SANDY CAVENAGH

1 Department of Health. The NHS reforms and you. London: HMSO, 1990.

Clarke K. Speech to Conservative Party Conference. London: Conservative Central Office, 1989. (Conservative Party conference news 185/89.)

3 House of Commons Official Report (Hansard). Written replies. Maternity services. 1990 July 5 , col 269; July 13, col 357-8; July 16, col 423-8; 1991 Feb 22, col 709.

4 Smith LFP, Jewell D. Contribution of general practitioners to hospital intrapartum care in maternity units in England and Wales in 1988. BMF 1991;302:13-6.

5 Office of Population Censuses and Surveys. Birth statistics. London: OPCS, published annually. (Series FM1.)

6 Jewell D. General practitioner obstetrics. BMF 1989;298:690-1.

Bryce FC, Clayton JK, Rand RJ, Beck F, Farquharson DIM, Jones SE. General practitioner obstetrics in Bradford. BMF 1990:300;725-7.

8 Sangala V, Dunster G, Bohin S, Osbourne JP. Perinatal mortality rates in isolated general practitioner maternity units. BMJ 1990;301:418-20.

9 Campbell R, Macfarlane AJ. Where to be born? The debate and the evidence. Oxford: National Perinatal Epidemiology Unit, 1987.

10 Cavenagh AJM, Phillips KM, Sheridan B, Williams EMJ. Contribution of isolated general practitioner maternity units. $B M \mathcal{F} 1984 ; 288: 1438-40$.

11 Garret T, House W, Lowe SW. Outcomes of women booked into an isolated general practitioner maternity unit over eight years. Journal of the Royal College of General Practitioners 1987;37:488-90.

12 Young G. Are isolated maternity units run by general practitioners dangerous? $B M \mathcal{J}$ 1987;294:744-6.

13 Taylor GW, Edgar W, Taylor BA, Neal DG. How safe is general practitioner obstetrics? Lancet $1980 ;$;i: $1287-9$.

14 Black N. Do general practitioner deliveries constitute a perinatal mortality risk? $B M \mathcal{J}$ 1982;284:488.

15 Klein M, Zander L. Role of the family practitioner in maternity care. In: Chalmers I, Enkin $M$ Kierse M, eds. Effective care in pregnancy and childbirth. Oxford: Oxford University Press, 1989.

16 Marsh GN, Channing DM. Audit of obstetrics in general practice. BMf 1989;298:1077-80.

17 Street P, Gannon MJ, Holt EM. Community obstetric care in West Berkshire. BMJ 1991;302:698-700.

18 Prentice $\mathrm{A}$, Walton SM. Outcome of pregnancies referred to a general practitioner maternity unit in a district hospital. BMF 1989;299:1090-2.

19 Smith LFP. General practitioner obstetrics in Bradford. BMJ 1990;300:875.

20 Bahrami J, Hagwood K, Givans RJ. General practitioner obstetrics in Bradford. BMF 1990;300:873.

21 Ross $M$, Brooke M, Connolly J, Connolly C, Daby J, Deakin I, et al General practitioner obstutric in Bradford. BMf 1990;300:1139-40

22 Rhodes JD, Roberts HE, Tedd CB, Tonks W, Pearson NR. General practitioner obstetrics in Bradford. BMF 1990;300:1140-1.

23 Ford C, Iliffe S, Franklin O Outcome of planned home births in an inner city practice: audit of 13 years' experience. BMF 1991;303:1517-9.

24 Young G. General practitioner maternity units. $B M 7$ 1990;301:665-6.

25 Chary $M$. General practitioner maternity units. BMF 1990;301:664-5.

26 Campbell R, Macfarlane AJ. General practitioner maternity units. BMf 1990;301:983-4.

27 Office of Population Censuses and Surveys. Mortality statistics. London: OPCS, published annually. (Series DH3.)

28 Office of Population Censuses and Surveys. Infant and perinatal mortality. Birthweight. London: OPCS Monitor, 1988. (DH3 88/1.)

29 Tew M. Place of birth and perinatal mortality. Fournal of the Royal College of General Practitioners 1985;35:390-4.

30 Tew M. Safer childbirth? A critical history of maternity care. London: Chapman and Hall, 1990.

31 Macfarlane AJ. No place like hospital? Nature 1990;347:721-2.

32 Klein M, Lloyd I, Redman C, Bull M, Turnbull AC. A comparison of low risk pregnant wome booked for delivery in two systems of care. Br J Obstet Gynaecol 1983;90:118-22.

33 Klein $M$, Elbourne D, Lloyd F. Booking for maternity care, a comparison of two systems. London: Royal College of General Practitioners, 1985. (Occasional Paper 31.)

34 Mehl LE. The outcome of home delivery: research in the United States. In: Kitzinger S, Davis JA, eds. The place of birth. Oxford: Oxford University Press, 1978.

35 Shearer JML. Five year prospective study of risk of booking for home birth. BMf $1985 ; 201: 1478-80$.

36 House of Commons Social Services Committee. Perinatal and neonatal mortality. Second report from the Social Services Committee, sessions 1979-80. Vol I. London: HMSO, 1980. (HC663-I.)

37 Hemminki E. Perinatal mortality distributed by type of hospital in the central hospital district of Helsinki, Finland. Scand F Soc Med 1985; 13:113-8.

38 Rosenblatt RA, Deinben J, Shoemack P. Is obstetrics safe in small hospitals? Evidence from New Zealand's regionalised perinatal system. Lancet 1985 ;ii:429-31.

39 Lumley J. The safety of small maternity hospitals in Victoria 1982- 84. Community Health Stud 1988:xii(4);386-93.

40 Sax S. Report of the Commission of Inquiry into South Australian Hospitals. Adelaide: South Australian Health Commission, 1983.

41 Taylor A. Maternity services: the consumer's view. Journal of the Royal College of General 응 Practitioners 1986;36:157-60.

42 Gillie $O$. Hospital v home childbirth row looms. Sunday Times 1980 Nov 16:6.

43 Mugford $M$. Economics of scale and low risk maternity care: what is the evidence? Maternity Action 990; $46: 6-8$

44 Drayton SM. Midwifery care wards, a model for the future. Proceedings of the international confederation of midwives twenty second international congress. Japan: Japanese Midwives Association, 1990:474-5.

45 Young GL. General practice and the future of maternity care. Br f Gen Pract 1991;41:66-7. 